\title{
Perioperative PONV Management, a Survey from Swedish Nurse Anesthetists' Perspectives
}

\author{
Jildenstål $\mathbf{P}^{1 *}$, Westerling $\mathrm{S}^{2}$, Myrén $\mathrm{E}^{3}$ and Warrén Stomberg $\mathbf{M}^{4}$ \\ ${ }^{1}$ Department of Anesthesiology, Surgery \& Intensive Care Medicine Sahlgrenska, University Hospital of Gothenburg, Sweden \\ ${ }^{2}$ Department of Surgery and Anesthesiology, Kungalv hospital, Sweden \\ ${ }^{3}$ Department of Surgery and Intensive Care, Hospital of Halland, Sweden \\ ${ }^{4}$ Associate Professor, University of Gothenburg/The Sahlgrenska Academy Institute of Health and care Sciences, Sweden
}

Submission: April 11, 2018; Published: April 17, 2018

*Corresponding author: Jildenstål P, Department of Anesthesiology, Surgery \& Intensive Care Medicine Sahlgrenska University Hospital of Gothenburg \& University of Gothenburg/The Sahlgrenska Academy Institute of Health and care Sciences, Gothenburg, Sweden, Tel: 0046760266658; Email: pether.jildenstal@gu.se

\begin{abstract}
Nausea and vomiting after general anesthesia (PONV) is still a problem, where approximately $20-30 \%$ of all patients are affected. Guidelines have been developed to identify those with a higher risk and to recommend a suitable type of treatment. Studies have shown a poor guideline adherence.

Introduction: The aim of this survey was to describe the nurse anesthetist perioperative caring and pharmacological actions to prevent and treat PONV in adult patients.

Method: A survey around the perioperative management of PONV was conducted. A questionnaire was distributed to nurse anesthetists at four different hospitals in the southwestern area of Sweden.

Results: Most of the nurse anesthetists who took part in the survey performed regular risk assessments for PONV in their daily work with patients. All departments performed some kind of prophylactic treatment for PONV, where the assessment and treatment often were based on the ward's routines or their own knowledge. Throughout the whole perioperative process, the nurse anesthetist adjusts, assesses and makes adjustments to minimize the patient's risk of experiencing postoperative nausea and vomiting, including patients who do not need PONV treatment in the initial phase of the perioperative care. The nurse anesthetist stated that they worked in different ways in order to prevent PONV. However, to prevent and treat PONV, the respondents preferred pharmacological treatment.
\end{abstract}

Conclusion: The nurse anesthetists generally experienced that PONV was not a problem among the patients. Still, risk assessments such as apfel-score was rarely used. The study also highlights that there is room for improvement regarding the use of non-pharmacological treatment and nursing care to minimize the risk of developing PONV.

Keywords: Postoperative nausea and vomiting (PONV); Clinical work; Nurse anesthetists; Assessment; Treatment; Prevention; Perioperative; General anesthesia

\section{Introduction}

Postoperative nausea and vomiting (PONV) is a common side effect after anesthesia and cause suffering to the patient and is resource-intensive in terms of both staff and social costs. Risk factors is well known and when patients have three or more risk factors, the incidence for PONV will be about 61\%-79\% [1].

Throughout the perioperative process, adjustments, assessments and measures shall be made to minimize the risk of the patient experiencing nausea and vomiting postoperatively. The choice and length of anesthesia affects the risk of PONV. There are still different perceptions of whether to predict PONV based solely on the type of surgery [2]. International and national guidelines to prevent and treat PONV need to be implemented and adapted to each individual clinic [3]. Previous research is mainly focused on risk factors and compliance with guidelines from a medical perspective.

Studies on how nurse anesthetists plan, assess, prioritize and perform actions based on the patient's risk of developing nausea and vomiting postoperatively is limited. Therefore, the aim was to describe the nurse anesthetist perioperative caring and pharmacological actions to prevent and treat PONV in adult patients. 


\section{Material and Methods}

This study was conducted as a descriptive cross-sectional survey, where data collection was done through questionaries' during a random week in April 2017. Clinically active nurse anesthetists in four hospitals and five different departments were asked for participation. In total, 68 nurse anesthetists were on duty during the study period and after informed consent, 60 nurses participated.

The questionnaire was based on literature in the field, such as recommend by Polit and Beck [4] and covered the entire process before, during and immediately after the operation. The questions were formulated with alternative closed-ended or rank-order answers and included 25 questions.

Prior to the study, a pilot study was carried out where four clinically active nurse anesthetists validated the questionnaire. The validation required no change to the questionnaire. The questionnaires were personally delivered to participants at the same time as written and verbal information was given, and the answers were handled confidentially. This article is based on a master's thesis and ethical positions taken in the framework of a student thesis at Sahlgrenska Academy, University of Gothenburg [5]. The study met the ethical requirements by the Helsinki Declaration [6].

Each questionnaire was assigned a random serial number and individual answers were coded to perform data entry, analysis and statistical calculations in SPSS (Version 23). The result was compiled with descriptive statistics and outlined in figures and text.

\section{Results}

Table 1: Demographic data $n=60,\left(\right.$ mean value ${ }^{*}$, number $={ }^{* *}$ )

\begin{tabular}{|c|c|}
\hline Sex, M/F & $\mathbf{2 0 / 4 0 * *}$ \\
\hline $\begin{array}{c}\text { Yrs as Nurse Anesthetist } \\
(\mathrm{n}=59)\end{array}$ & $13(0-35)^{*}$ \\
\hline
\end{tabular}

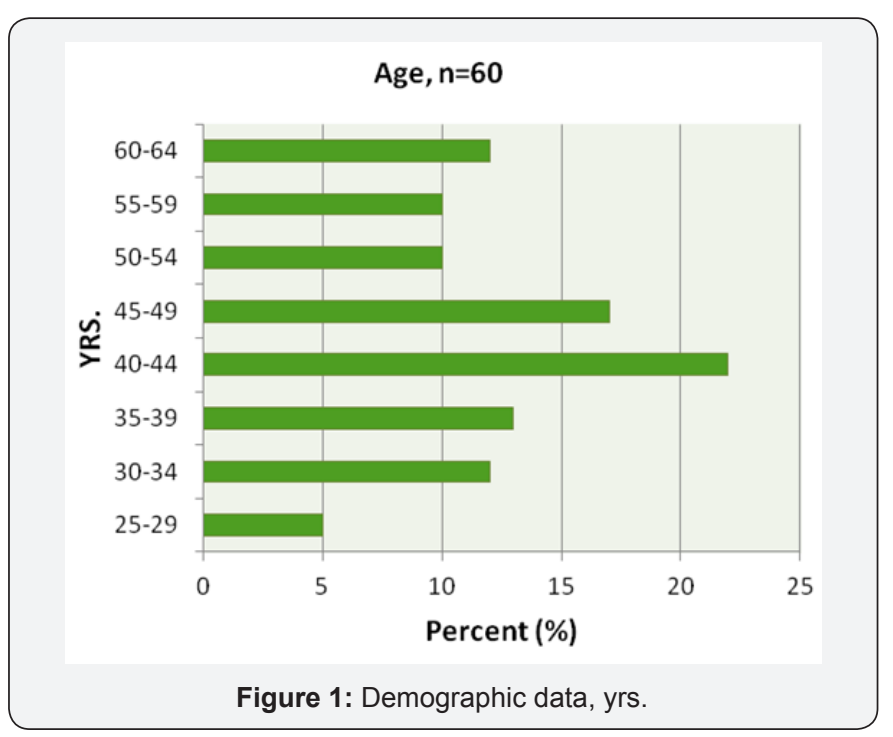

The overall response rate to the survey was 95\% $(n=63 / 60)$. Demographics of the respondents are presented in Table 1 \& Figure 1. Assessment of the patient's PONV risk was generally performed by all the nurse anesthetists. However, $41 \%$ stated that patients with no risk factors for developing PONV also get pharmacological PONV prophylaxis (Figure 2).

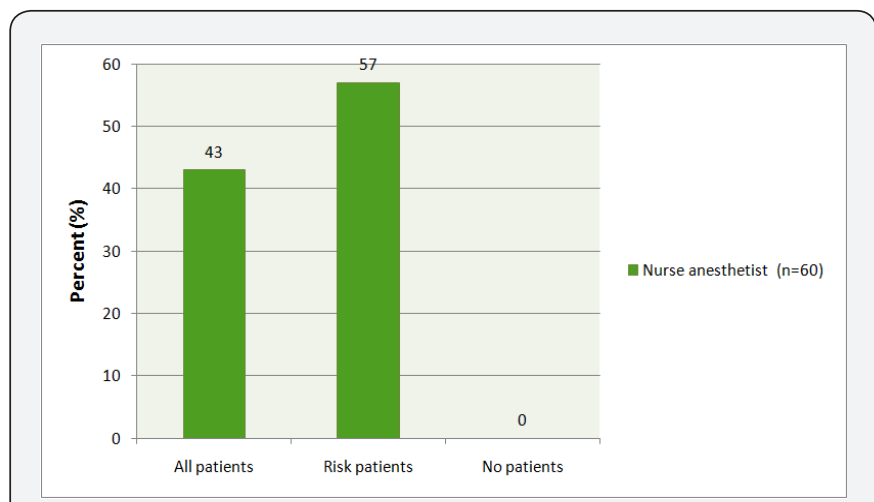

Figure 2: Percent of patients receiving prophylaxis for PONV.

The department's routines and the nurse anesthetist's own knowledge formed the basis of both this assessment and the prophylaxis that was given (Figure $3 \& 4$ ). Majority of the nurses stated that they focused on PONV prevention during the whole perioperative period.

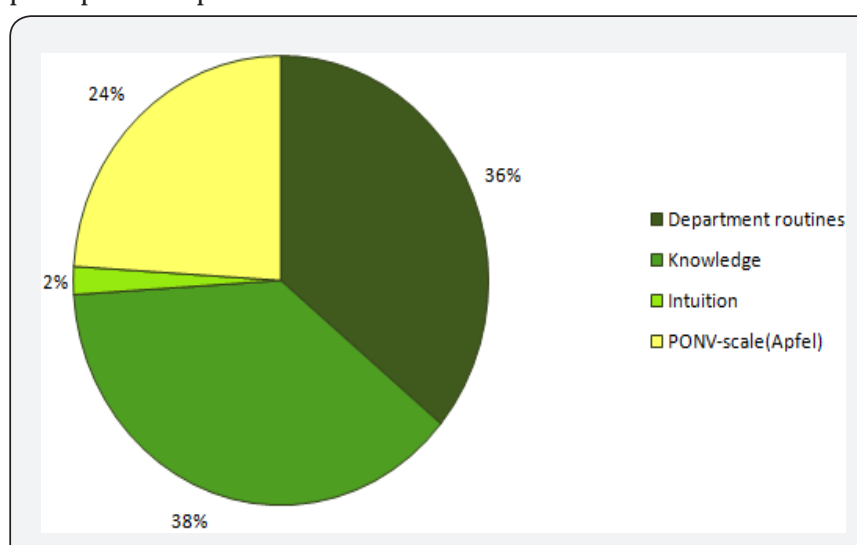

Figure 3: The bas method for risk assessment of PONV $(n=55)$.

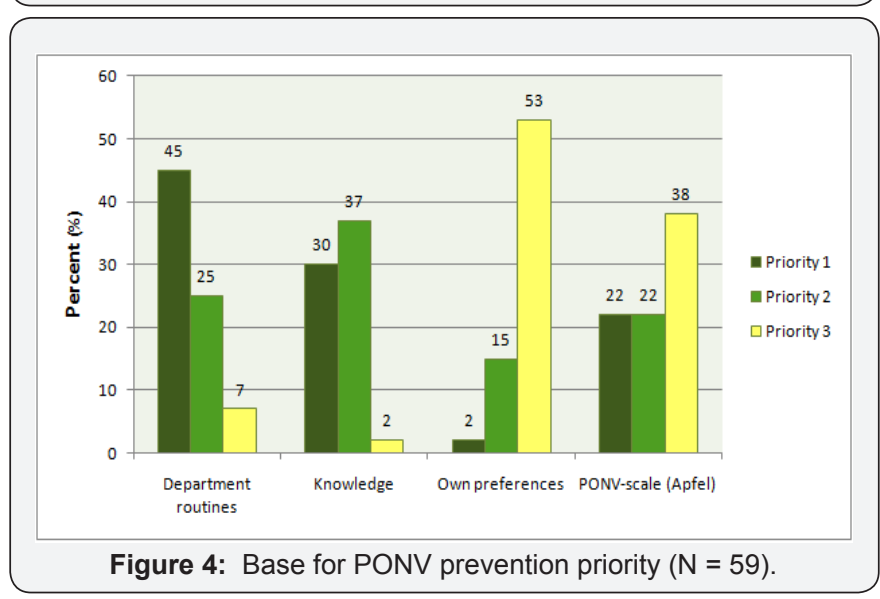

All respondents were asked to prioritize three preoperative actions regarding PONV. Almost all of respondents stated that 
pharmacological prophylaxis (92\%) had first priority and secondly pain relief (50\%) and third was to optimize fluid balance (37\%).

Prophylaxis against PONV was used to a great extent. Ondansetron $\AA$ and Betamethasone ${ }^{\circledR}$ were used almost exclusively to prevent PONV (Figure 5). The majority of the nurse anesthetists considered that ondansetron ${ }^{\circledR}$ had the best

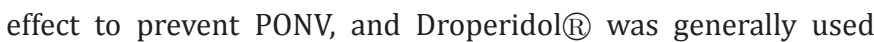
to a lower extent as prophylaxis. However, a prophylactic nonpharmacological effect which was reported to a greater extent from the respondents was to reduce the patient's overall concern and stress.

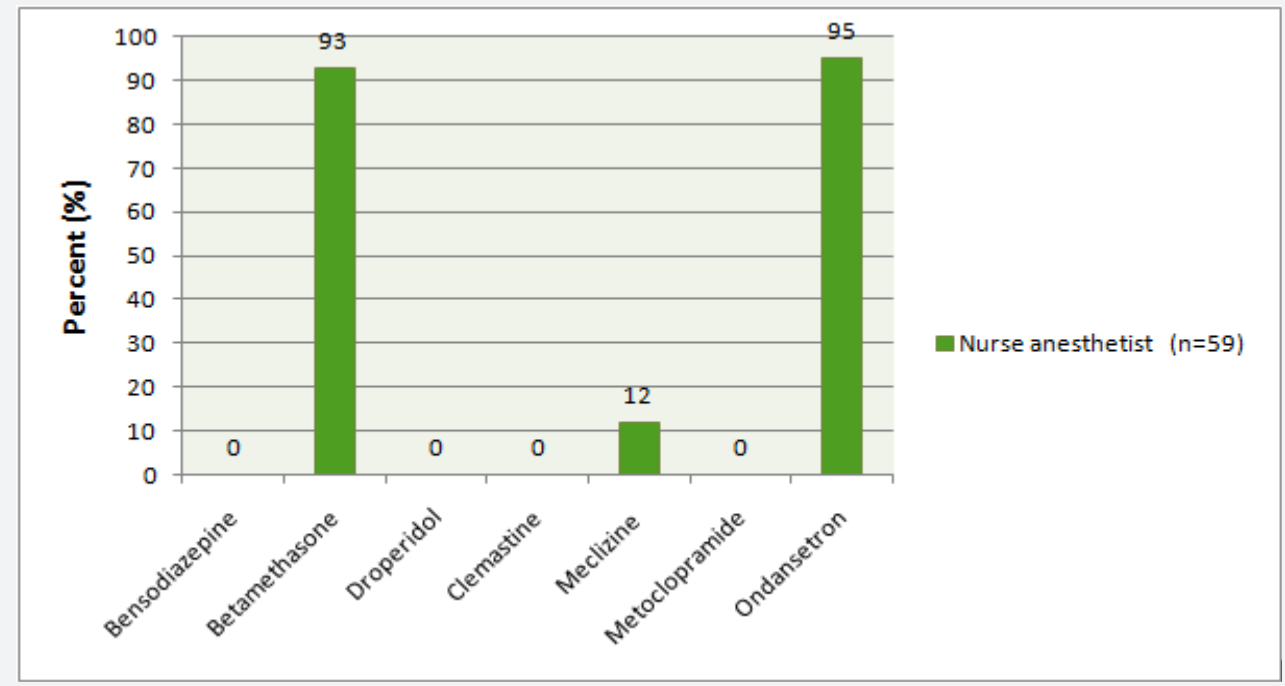

Figure 5: The two antiemetic drugs mainly used clinically to prevent PONV (Two options possible per respondent, $n=60$ ).

The factors considered by the nurse anesthetist's to affect the patient's risk of PONV, besides pharmacological prophylaxis, was anesthetic method. However, the use of EEG fine tuning depth of anesthesia monitoring during intraoperative period to decrease risk of PONV was not prioritized as a method. Within the framework of what the nurse anesthetists tried to influence to prevent PONV, there was also the intraoperative pain relief.

The postoperative pain relief was adapted to the patient's PONV risk, which was mainly done by using multimodal pain relief and thereby reducing the opioids. However, when asking the respondents regarding which opioid has the lowest incidence of PONV, they stated that Oxycodone and Alfentanil had the lowest incidence of risk for PONV.

Other postoperative methods to decrease incidence of acute PONV were besides administration of pharmacological antiemetic's, increasing/coupling oxygen, avoiding rapid movements, high noise levels, strong smells or strong light.

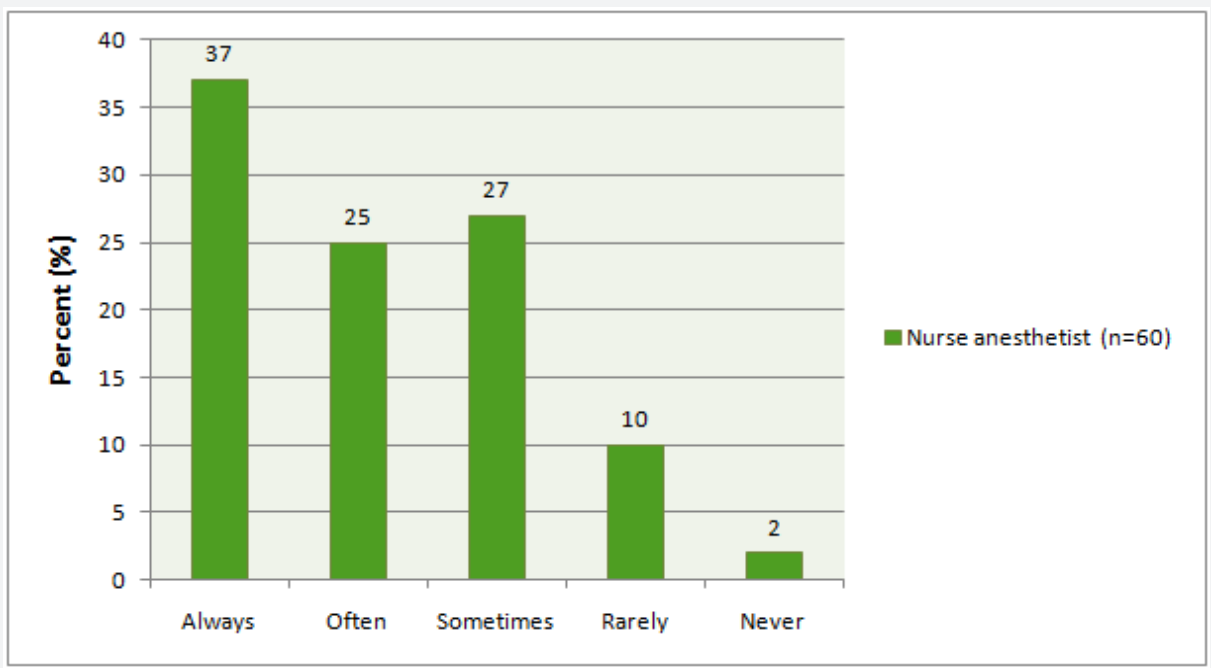

Figure 6: Nurse anesthetist reporting the patient's PONV risk when hand over the patient at the post-operative department. 
When the patient was transferred to the post-operative department / ward, the patient's PONV risk was often reported to the nurse in charge. Follow-up of the given prophylactic treatment against PONV was rarely done by nurse anesthetist's in the present study (Figure 6).

\section{Discussion}

It was found that respondents generally did not notice PONV as a major problem perioperatively. Perhaps this is due to that the nurse anesthetists generally used the department's routines for assessing and preventing the patient's PONV risk, which was performed preoperatively. Similar, PONV prevention was given to all patients, regardless of risk. However, PONV in routine clinical care tend to be under-reported. Therefore, the patients must be asked routinely about nausea and vomiting at frequent intervals up to $24 \mathrm{~h}$ post-operatively [7].

Avoiding PONV is both from the patients and nurses perspective a significant factor in influencing postoperative recovery [8]. Already during the preoperative meeting, nurse anesthetists inform the patient of possible nausea after surgery and how it can be treated. This may give the patient the ability to handle PONV in a better way [9]. It is known that preoperative anxiety is a risk factor for PONV. By providing information about treatment options, the risk can be reduced and patient satisfaction increased [10]. A routine for assessing PONV risk, preventing and treating PONV is a starting point to avoid PONV and increase patient satisfaction. However, knowledge that a genetic predisposition among people who experience PONV as well as treatment effect differences shall not be forgotten.

Nurse anesthetists considerations in this study were specifically taken into account to avoid an anesthetic method that may make PONV worse and troublesome in treating. This is well in line with earlier studies where individual anesthetic methods are recommend and taken into consideration to prevent PONV $[11,12]$. Findings in this study do not highlight the nonpharmacological therapies as an adjunct to standard antiemetic drug therapy, despite transcutaneous electric nerve stimulation and P6 acupoint pressure is found to be valuable adjunct therapies $[13,14]$.

Throughout the perioperative course of care, a pharmacological prophylactic strategy was mainly preferred in this study instead of non-pharmacological prophylaxis and treatment. Similarly, pain and fluid balance was important aspects on PONV prevention. This is in accordance to earlier findings, that treating severe PONV requires multimodal pharmacological therapy that affects multiple receptors, adapted anesthesia, optimal fluid balance, pain control and minimization of intra and postoperative opioids [15].

However, it is still necessary to continue with the challenge of designing and developing novel modalities of antiemetic drugs and other nonpharmacological therapies to find optimal treatment methods [15]. Therefore, additional studies are needed to overcome this unpleasant problem.
There are shortcomings in the study, for example, data is based on few participants with varying professional experience. However, the response rate was quite high, 95\%. Some internal drop outs of the answers were found, however not being considered as crucial to the outcome.

\section{Conclusion}

The nurse anesthetists generally experienced that PONV was not a major problem among the patients. Still, risk assessments such as apfel-score was rarely used. This survey confirms that there is a strong position of the pharmacological treatment in preventing and treating PONV throughout the whole perioperative process. The use of a multimodal strategy, using both pharmacological and non-pharmacological treatment and nursing care to minimize the risk of developing PONV need further to be studied.

\section{Acknowledgement}

We thank all RNAs who participated and exhaustive gave their answers.

\section{Conflict of Interest}

None of the authors have any conflict of interest. Funding, this research did not receive any specific grant from funding agencies in the public, commercial, or not-for-profit sectors.

\section{Authors' Contributions}

PJ, SW and EM has planned the study. PJ prepared the first version of manuscript and

PJ, MWS, SW and EM has taken part in the result presentation and writing of manuscript.

All authors were involved in manuscript and approved the final version.

Sofia Westerling and Emma Myrén conducted the data and performed a master thesis from the data.

\section{References}

1. Roberts SM, Bezinover DS, Janicki PK (2012) Reappraisal of the role of dolasetron in prevention and treatment of nausea and vomiting associated with surgery or chemotherapy. Cancer Manag Res 4: 67-73.

2. Obrink E, P Jildenstal, E Oddby, JG Jakobsson (2015) Post-operative nausea and vomiting: update on predicting the probability and ways to minimize its occurrence, with focus on ambulatory surgery. Int J Surg 15: 100-116.

3. Hooper VD (2015) SAMBA Consensus Guidelines for the Management of Postoperative Nausea and Vomiting: An Executive Summary for Perianesthesia Nurses. J Perianesth Nurs 30(5): 377-382.

4. Polit DF, CT Beck (2016) Nursing research: generating and assessing evidence for nursing practice. Wolters Kluwer, Philadelphia.

5. [The Swedish Code of Statutes] Författningssamling, S.-S., [Law (2003: 460) concerning the ethical review of research involving humans] Lag (2003: 460) om etikprövning av forskning som avser människor. Stockholm: Utbildningsdepartementet, 2003.

6. Helsinki WMADO (2002) Codes and Declarations. Nurs Ethics 2002(9): 105. 
7. Franck M, Radtke FM, Apfel CC, Kuhly R, Baumeyer A, et al. (2010) Documentation of post-operative nausea and vomiting in routine clinical practice. J Int Med Res 38(3): 1034-1041.

8. Lee A, T Gin, AS Lau, FF Ng (2005) A comparison of patients' and health care professionals' preferences for symptoms during immediate postoperative recovery and the management of postoperative nausea and vomiting. Anesth Analg 100(1): 87-93.

9. Borjeson S, C Arwestrom, A Baker, C Bertero (2010) Nurses' experiences in the relief of postoperative nausea and vomiting. J Clin Nurs 19(13-14): 1865-1872.

10. Roh YH, HS Gong, JH Kim, KP Nam, YH Lee, GH Baek (2014) Factors associated with postoperative nausea and vomiting in patients undergoing an ambulatory hand surgery. Clin Orthop Surg 6(3): 273278

11. Skolnik A, TJ Gan (2014) Update on the management of postoperative nausea and vomiting. Curr Opin Anaesthesiol 27(6): 605-609.
12. Lichtor JL (2012) Nausea and vomiting after surgery: it is not just postoperative. Current Opinion in Anesthesiology 25(6): 673-679.

13. Cekmen N, B Salman, Z Keles, M Aslan, M Akcabay (2007) Transcutaneous electrical nerve stimulation in the prevention of postoperative nausea and vomiting after elective laparoscopic cholecystectomy. J Clin Anesth 19(1): 49-52.

14. Lv JQ, RZ Feng, N Li (2013) P6 acupoint stimulation for prevention of postoperative nausea and vomiting in patients undergoing craniotomy: study protocol for a randomized controlled trial. Trials 14: 153.

15. Kovac AL (2013) Update on the management of postoperative nausea and vomiting. Drugs 73(14): 1525-1547.

16. Garg S, S Subramani, H Sachdeva (2017) Postoperative nausea and vomiting: The achilles heel of anesthesiologists. J Anaesthesiol Clin Pharmacol 33(4): 427-428.

\section{Your next submission with Juniper Publishers} will reach you the below assets

- Quality Editorial service

- Swift Peer Review

- Reprints availability

- E-prints Service

- Manuscript Podcast for convenient understanding

- Global attainment for your research

- Manuscript accessibility in different formats

( Pdf, E-pub, Full Text, Audio)

- Unceasing customer service

Track the below URL for one-step submission

https://juniperpublishers.com/online-submission.php 